\author{
Наталия Пятаева \\ Стерлитамакский филиал Башкирского государственного университета (Уфа, Россия)
}

\title{
К ПРОБЛЕМЕ КОНТРАСТИВНОГО ОПИСАНИЯ ЛЕКСИКО-СЕМАНТИЧЕСКИХ СИСТЕМ ВОСТОЧНОСЛАВЯНСКИХ ЯЗЫКОВ В ДИАХРОНИЧЕСКОМ АСПЕКТЕ
}

Лексическое гнездо (далее: ЛГ) - сложная комплексная единица системы словообразования, в которой тесно переплетены и постоянно взаимодействуют разноуровневые семантические и структурные преобразования, способные привести к расщеплению и разрушению некогда единого гнезда. Изучение лингвистических и экстралингвистических факторов, определяющих формирование, функционирование и распад лексических гнёзд - важнейшая задача диахронической дериватологии, признающей наиболее результативными и обнадёживающими исследования лексических гнёзд на всём протяжении истории родственных языков. Такой подход позволяет выявить особенности формирования и функционирования ЛГ, специфику взаимоотношений между словами в пределах гнезда, установить статику и динамику в изучаемых гнёздах, увидеть перспективу движения исследуемых фактов к современному состоянию. Исследование семантических изменений слов гнезда в их историческом развитии позволяет точно и доказательно определить условия разрыва словообразовательных связей и превращения словообразовательного гнезда в корневое или этимологическое, однако в историческом развитии лексического состава языка можно обнаружить более крупные системные образования, чем традиционно выделяемые словообразовательные (СГ), корневые (КГ) и этимологические гнёзда (ЭГ).

Так, в процессе исследования праславянской и общевосточнославянской (далее: о.-в.-с.) семантики лексических гнёзд, возглавляемых индоевропейскими (далее: и.-е.) корнями *еm- и *ber- 'брать, взять', была обнаружена генетическая связь их значений с семантикой и.-е. корней *dō- (давать, дать) и *nes-(ti) (нести) (Пятаева 2010, 2011). Семантический ряд, образуемый вершинами этих ЛГ, мы назвали генетической парадигмой. Опорные слова этого ряда (давать//дать $\rightarrow$ брать $\rightarrow$ взять $\rightarrow$ иметь $\rightarrow$ нести $\rightarrow$ давать) объединены последовательностью выражаемых ими значений, содержащих 
общие семы: ‘приобщаемый объект’ и ‘действие субъекта, направленное на приобщаемый объект’. Семантическое пересечение этих лексем обусловлено синкретизмом значений древних корней, к которым они восходят:

1) и.-е. *dō- имел значения 'давать//дать', ‘брать', ‘нести': о.-в.-с. датн даватн, да́ннна 'дар', дань 'дар, доход, подать, дань; подданство', Аарнтн, дароватн, Ааровнтын 'щедрый', даръ; укр. дати - дава́ти, дань, дани́на, да́нок 'даяние, дар', дари́ти, дарува́ти, да́ра 'милость, дар', дарови́тий 'даровой', дармоїд; блр. дащь - дава́щฺ, даніна, дача 'даяние', неўда́ча 'неудача; (разг.) недотёпа, неумелый, нерасторопный человек’, дарьіць, дар, дармá ‘понапрасну', рус. дать - дава́mь ${ }^{1}$, дань, данность, дача, дарить, дар, дармоед; см. также примеры проявления древней связи значений: болг. и́мам взе́мане - да́ване 'иметь общие дела с кем-л.', о.-в.-с. даньннкъ 'платящий дань' и 'сборщик дани', укр. нада́щ̧ь 'присвоить звание, т.е. взять самовольно', да́чка и сбор 'денежный, податной сбор', нада́тысь 'напастись, насобирать';

2) и.-е. *bher- 'нести' (отсюда о.-в.-с. веремА, укр. бере́жа, блр. бере́мо, рус. бремя, беремя) в праславянском развивает значение 'брать' (о.-в.-с. вьратн, укр. бра́ти, блр. бращьь, рус. брать), становясь синонимичным и.-е. *ет- 'брать/взять' (о.-в.-с. нматн, нанмати, укр. іма́ти, наніма́ти, блр. іма́ць, наня́uь, в рус. с утратой нматн сохранились только его префиксальные производные: вынимать - вынуть, нанимать - нанять и др.), который в более поздних суффиксальных дериватах приобретает значение 'иметь, обладать, владеть' (о.-в.-с. нм'тн, ст.-укр. има́ти 'иметь' и 'ловить', укр. мати, іміти 'иметь', блр. іма́иь 'брать, принимать' и 'иметь', мець 'иметь', рус. иметь), существующее параллельно с изначальным на всём протяжении истории восточнославянских языков.

Пересечение значений в рефлексах опорных слов этой генетической парадигмы можно наблюдать в современных славянских языках:

1) более привычным и закономерным является наличие разнокорневых синонимов, восходящих к о.-в.-с. глаголам нмати и вьрати 'брать, хватать, ловить': укр. бра́ти - іма́ти, я́mu, ня́mи 'брать, хватать', розбіра́ти(ся), розібра́ти(ся) - сніма́ти(ся) 'раздевать, снимать одежду; раздеваться'; блр. абніма́uฺ , абыма́uฺ - аня́uь, разобра́иฺ 'заключать в объятия, охватывать охватить, овладеть', блр. бращь, бра́uщ $а$ - нящз и рус. брать - взять, супплетивно образующие видовую пару 'брать - взять, схватить';

2) совмещение в одном именовании значений 'дать, давать' и 'брать', обусловленное восприятием последовательных и взаимообусловленных

1 Лексический материал, использованный в статье в качестве иллюстраций, извлечён из историко-этимологических и этимологических словарей русского и славянских языков, библиографическое описание которых помещено в списке литературы (Гамкрелидзе, Иванов 1984; СРЯ 1958; Срезневский 1989; Фасмер 1996; Черных 1994; Шапошников 2010; ЭССЯ; ЭССЯ а) 2007; Buck 1971; SP). 
действий передачи и приобщения - «принятия» объекта как единого процесса (или сценария, в терминологии когнитивной лингвистики): 'давать, передавать кому-л. что-л.' $\rightarrow$ 'брать, принимать что-л. от кого-л.' и обратный процесс 'взять для того, чтобы отдать, передать что-л. кому-л.', ср. о.-в.-с. овнятн 'заключить в объятия, окружить чем-л., занять (собой), захватить, овладеть, сделать оправу, скрепить; охватить умом, понять' и 'ободрать кору с дерева', Ааньннкъ 'платящий дань' и 'сборщик дани'; укр. iмámu ‘брать, хватать, ловить' и 'давать', наніма́mи - найня́mu 'нанимать//нанять, брать//взять в пользование на определённый срок за плату' и 'отдавать// отдать в наём, на службу', разг. найня́ти-ся//наня́тися 'поступать на работу или службу по найму' и 'быть сдаваемым в наём, в аренду', разбіра́ти розібра́тu 'разбирать на части; разбирать по качеству или назначению вещи; разделывать тушу; понимать' и 'раздевать', дарува́ти 'дарить, награждать, жертвовать' и 'прощать, извинять', т.е. 'вновь приближать к себе, приобщать', нада́ųь 'дать в несколько приёмов; поколотить, наговорить' и 'захотеть' и в возвратной форме того же глагола нада́mыся 'напастись', обно́сити 'носить кругом, вокруг; разносить всем, потчевать; огораживать, окружать; оговаривать, порочить' и 'обрывать, обламывать и разносить вокруг (о ветре), срывать плоды’; блр. разда́ųь - раздава́u̧ь 'раздать, раздавать (отторгать от себя)' и 'наделить/наделять кого-л. чем-л.', абіра́u̧ь - абабра́u̧ь 'обирать плоды' и 'чистить (скорлупу, кожуру); обкрадывать, отбирать' - абіра́нне 'сбор' и 'чистка, очистка как отторжение', разбіра́щ̧ца 'понимать, соображать' и 'раздеваться';

3) совмещение в глаголах значений 'нести' и 'иметь' (так как нести можно только то, что взято, приобретено, то есть то, что стало собственностью, то, что имеешь): о.-в.-с. носити 'держа, перемещать, переносить; приносить, доставлять; увлекать с собой (силой своего движения); носить, иметь надетым; заключать в себе, содержать; служить опорой, поддерживать собой; воспринимать, постигать; подвергаться чему-л.; иметь; быть одетым во что-л.; выносить, произносить решение'; ср. в современных восточнославянских языках: укр. нести - носити, блр. несці - насіц̧ь, рус. нести - носить 'взяв в руки или нагрузив на себя, перемещать, доставлять куда-л.', перен. 'имея что-л., передавать', 'быстро, стремительно передвигать, везти, мчать; передвигать, увлекать силой своего движения (о ветре, течении воды); распространять звук, запах', 'исходить от кого-, чего-л., передаваться по воздуху; быть слышимым, ощутимым (о запахе)', перен. 'бросаться в глаза, отличаться каким-л. свойством, качеством'; 'выполнять поручение, обязанности'; 'влечь за собой как следствие; приносить с собой'; (разг.) 'говорить что-л. вздорное, неразумное'; 'иметь, содержать'; перен. 'иметь, заключать в себе, быть носителем чего-л., каких-л. чувств, идей’;

4) наличие дополнительной семы 'нести' отмечено в значениях глаголов корневых групп *еm- и *ber-: болг. до́бера се 'добраться, дойти, доехать', 
éмна, по́ема 'отправиться куда-л.'; польск. dobrać się 'добраться', przebrać się 'пробраться', zabrać się 'собраться, уйти, отправиться, убраться'; укр. забра́тися звідки-л. 'убраться откуда-л., скрыться', зня́тися з місия 'сняться с места, покинуть какое-л. место быстро, стремительно', ня́ти вірі 'верить, нести веру в себе', обійняти 'обнимать, охватывать кого-л. руками' и 'иметь в своём составе, включать в сферу своего внимания, деятельности'; блр. дабра́ииа да ме́сияа 'добраться до определённого места - туда, куда необходимо', прыбра́щиа адкуль-л. 'убраться откуда-л., скрыться', зня́щциа з месияа и рус. сняться 'покинуть какое-л. место, отправляясь в путь', разг. 'поехать, пойти в каком-л. направлении', диал. доня́mь 'дойти, доехать, добраться до кого-л.';

5) ср. также проявление семантики 'перемещение в пространстве' в современном ЛГ с вершиной *nesti: укр. нести́ - нести́ся 'нестись, быстро двигаться', носи́ти (наряду с др.) 'ходить, ездить', підноси́тися - niднести́ся 'возноситься - вознестись', переноси́тися - перенести́ся 'переноситься перенестись'; блр. не́сиі 'нести, уносить, мчать', не́сиісяя 'быстро двигаться, нестись, мчаться; удаляться, уноситься', диал. носіщиа 'носиться, бегать туда-сюда', ўзносіица - уззнесиіся 'возноситься - вознестись', пераносіщи - neранесиіся 'переноситься - перенестись', выносіщиа - панесиіся 'уноситься унестись'; рус. высок. вознестись 'подняться вверх, ввысь', разг. донестись 'быстро доехать, домчаться', нестись 'очень быстро двигаться, перемещаться, мчаться', разг. перенестись 'стремительно перебежать, переехать, перелететь через что-л., куда-л.; примчаться', пронестись 'быстро пройти', унестись 'быстро удалиться, умчаться', а также в невозвратных формах донести 'быстро донести, доставить, домчать', нести 'стремительно передвигать, мчать'.

Попутно заметим, что более насыщенная семантика о.-в.-с. носнтн(сА) связывает это ЛГ со значениями корней *еm- и *ber-: 'увлекать силой своего движения' (како ти велнцнн оБьлацн ко горы преплываютъ кож по-

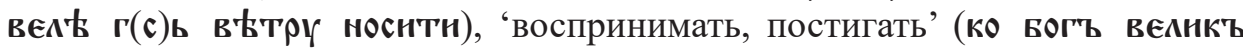
юсть носАн наша грҚХы и всего мнра Бещнсленую змову), 'Подвергаться

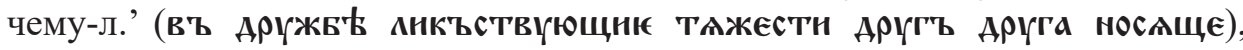
'иметь' (доврохвальна оуста носнтн), 'быстро, беспорядочно перемещаться, носиться; устремляться; влечься, ввергаться' (снмъ въ чмвц'

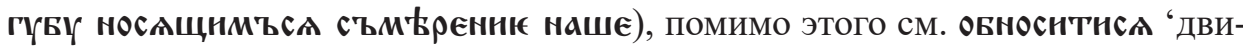
гаться, перемещаться; бегать (о глазах); иметься; становиться известным, распространяться' (...Безчнннымн въпиьмн овноснтнсА).

Кроме семантического синкретизма, существование подобной генетической парадигмы обусловлено хорошо известным в сравнительной грамматике славянских и других и.-е. языков явлением парадигматического супплетивизма, о котором писал О.Н. Трубачёв (Трубачёв 1998): и.-е. *bher- 'нести' выступало в дуративно-презентной функции, тогда как в функции других глагольных времён оно восполнялось этимологически совершенно особыми основами - и.-е. *(e)nek-, *t(e)l-, включая этимологически неясные случаи: греч. 
$\varphi \varepsilon ́ \rho \omega$ 'несу, ношу', $\tau \lambda \eta v \alpha$, $\tau \alpha \lambda \alpha ́ \sigma \sigma \alpha 1$, лат. ferō 'несу, ношу', форма перфекта tulī < др.-лат. tulō, tulere 'носить, приносить' (первоначально 'поднимать, выдерживать тяжесть'). Равным образом письменная история наблюдает факты разрушения, нивелировки супплетивности, когда лексическая самостоятельность основ получает преобладание над их грамматическими связями. Так, и.e. *bher- и *(e)nek- в славянских языках являются совершенно самостоятельными лексемами с особыми значениями *berQ, *bbrati ‘брать' и *nesti ‘нести', и только старые отглагольные именные производные вроде *bermę 'бремя, ноша' показывают, что и славянские языки сохраняют память о старых супплетивных отношениях, cp. c.-x. nésti, nésem 'нести, ношу' и zànijeti 'понести, забеременеть'. Именно в последних формах наблюдается самобытное сохранение языкового факта большой древности.

Особо отметим наблюдающиеся как в общевосточнославянском, так и в современных славянских языках лексемы с интересными метафорическими переносами в семантике, обусловленными синкретизмом значений древних корней, к которым они восходят, см., например:

1) о.-в.-с. непрннмьнын 'не подверженный чему-л., не доступный воздействию чего-л.' > 'вечный, несменяемый'; натнсл 'набраться' > 'набраться, наполниться чем-л. со стороны в большом количестве, проникающим внутрь

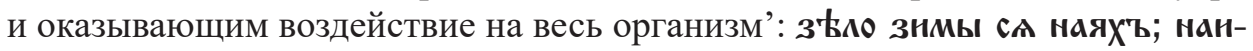
метса тьАо Хмелю акы гоүвы воды (Срезневский 1989, т. 2: 354); повель

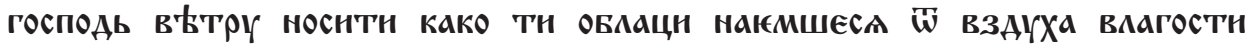
(СлДРЯ IX - XIV вв.: 222); єматнсА пУтн 'отправляться в путь'; Мюта змн черна, земля непрнюмна (заговор от змеи); оБүАтнсА 'обняться, проявить расположение; примириться с кем-л.' > 'быть охваченным, объединённым каким-л. общим чувством, состоянием'; даньннкъ 'платящий дань' - 'сборщик дани'; ...Безчнннымн въпмьмн овноснтнсл... перен. 'окружать себя чем-л.'; носнтт нмА, сан'ъ, овразъ 'иметь имя, сан, быть в звании';

2) укр. бра́ти, берý, бра́тися 'браться, приниматься' > 'идти, направляться; всходить, взбираться, взлезать'; набірати тіла 'полнеть, толстеть'; высоко нестися, в гору нестися 'заноситься, важничать'; ст.-укр. има́ти 'иметь, содержать в себе' > 'долженствовать' > 'ловить'; іма́ти 'брать' 'дать'; неприятель 'неприятель, недруг' > 'чёрт'; няти вірі 'верить'; дарува́ти 'дарить, награждать' > 'жертвовать' > 'прощать, извинять';

3) блр. абабра́иь 'собрать плоды; очистить кожуру, выбрать; обобрать, ограбить'> абабра́щия 'опомниться'; диал. разабра́щฺь 'разрушить, распутать' > 'выяснить'; абніма́uь - абня́uь 'заключать в объятия, обнимать; охватывать' > 'заглушить, зарасти'; ... пришлець и наимить да не едять во единомъ доме снесте; по словахъ своихъ познанъ бываетъ неприятель; неўда́ча 'неудача' > 'недотёпа, неумелый, нерасторопный человек'; разда́ų 'раздать, наделить чем-л.' > 'сделать просторнее'; ст.блр. ... мужь есть то добрыи, и добрую новину (новость, новизна, новщество) несетъ; 
4) русск. диал. неприязная сила, неприятная сила 'нечистая сила, черти'; окоём 'то, что можно охватить взглядом' > 'ленивый, непослушный человек; простак, олух'> 'скряга, скупец'> 'обманщик'; но́сом нести 'в свадебном обряде - во время или в конце свадьбы одаривать родственников невесты привезёнными женихом подарками';

5) польск. darować 'подарить, принести в дар' > 'отказаться от чего-л., простить';

6) болг. на́бур 'набор, то, что собрано' > 'сверстники'.

Таким образом, семантическое соотношение компонентов нашей генетической парадигмы можно представить в виде схемы:

даmb//дaвать (глагол действия, донативный глагол)

$\rightarrow$ брать//взять (глагол приобщения объекта)

$\rightarrow \boldsymbol{u м е т ь ~ ( г л а г о л ~ о б л а д а н и я , ~ п о с е с с и в н ы и ̆ ~ г л а г о л ) ~}$

$\rightarrow$ нести (глагол перемещения в пространстве)

$\rightarrow$ дать//давать.

С достаточной долей уверенности можно предположить, что эта генетическая парадигма представляет собой ментальную схему передачи - получения - обладания, являющуюся семантической универсалией, а её конкретное лексико-грамматическое воплощение в том или ином языке показатель специфики национальной языковой картины мира.

В заключение отметим, что рассмотрение изменений, которые происходят в процессе развития лексической системы языка, делает генетическую парадигму важным объектом исторической лексикологии. Именно в крупных лексических объединениях могут быть выявлены и прослежены связи и взаимодействия между словами, их активизация или ослабление, изменения соотношений сфер употребления слов, их функциональная стратификация, то есть все те изменения, которые происходят в лексической системе языка.

Одним из путей решения проблемы создания полного и систематического очерка общевосточнославянской и, шире, славянской исторической лексикологии может стать рассмотрение динамики развития целого комплекса лексических гнёзд на всём протяжении их существования в составе генетической парадигмы, ибо лингвистами давно отмечено, что слова со сходными значениями проходят сходную семантическую историю.

\section{Библиография}

Гамкрелидзе Т. В., Иванов В. В. (1984), Индоевропейский язык и индоевропейцы. Реконструкция и историко-типологический анализ праязыка и протокультуры, ч. I-II, Тбилиси.

Пятаева Н. В. (2010), Единиць диахронического исследования лексической системы русского языка (к проблеме выделения и квалификачии), [в:] Русский язык: исторические судьбы и современность: $1 \mathrm{~V}$ Международный конгресс исследователей русского языка (Мо- 
сква, МГУ им. М. В. Ломоносова, фил. фак., 20-23 марта 2010 г.): Труды и материаль, сост. М. Л. Ремнёва, А. А. Поликарпов, Москва, с. 320-321.

Пятаева Н. В. (2011), К проблеме исследования лексики праславянского языка, [в:] Проблемь кониептуализации действительности и моделирования языковой картины мира: Сб. науч. тр., вып. 5, сост. и отв. ред. Т. В. Симашко, Москва, Архангельск, с. 168-178.

СлДРЯ XI-XIV вв. (2002), Словарь древнерусского языка (XI-XIV вв.): в 10-ти т., РАН. Ин-т рус. яз., ред. Р. И. Аванесов, И. С. Улуханов, т. 5, Москва.

Срезневский И. И. (1989), Материаль для словаря древнерусского языка: в 3-х т., Москва.

СРЯ (1958), Словарь русского языка: в 4-х m., АН СССР. Институт русского языка, ред. колл.: С. Г. Бархударов и др., А. П. Евгеньева (председатель), Москва, т. ІІ: К-О.

Трубачёв О. Н. (1998), Славянская филология и сравнительность. От съезда к съезду, «Вопросы языкознания», № 3, с. 3-25.

Фасмер М. (1996), Этимологический словарь русского языка: в 4-х т., пер. с нем. и доп. О. Н. Трубачёв, ред. и предисл. Б. А. Ларин, Санкт-Петербург.

Черных П. Я. (1994), Историко-этимологический словарь современного русского языка: 13 560 слов: в 2-х т., Москва.

Шапошников А. К. (2010), Этимологический словарь современного русского языка: в 2-х т., Москва.

ЭССЯ, Этимологический словарь славянских языков: праславянский лексический фонд, РАН, Институт русского языка им. В. В. Виноградова, ред. О. Н. Трубачёв, вып. 2-4, 6, 9, 21 , 22, 24-26, 28, 30-32, Москва, 1975-1977, 1979, 1983, 1994, 1995, 1997-2001, 2003-2005.

ЭССЯ а) (2007), Этимологический словарь славянских языков: праславянский лексический фонд, РАН, Институт русского языка им. В. В. Виноградова, ред. А. Ф. Журавлёв, вып. 33, Москва.

Buck C. D. (1971), A dictionary of selected synonyms in the principal Indo-European languages: a contribution to the history of ideas, Chicago - Illinois.

SP (1974-1980), Słownik prasłowiański, t. I-IV, red. Fr. Sławski, Wrocław; Warszawa; Kraków; Gdańsk.

Natalia Pyataeva

\section{TO DESCRIBE THE PROBLEM OF THE CONTRASTIVE LEXICAL SEMANTIC SYSTEMS EAST SLAVONIC LANGUAGES IN DIACHRONIC ASPECT}

(Summary)

The paper addresses the issues of diachronic description genetically related vocabulary East Slavonic languages based on a study of its origin and semantics in accordance with the actual problems of the historical word formation lexicology and lexicography Slavonic languages. To study involved pre-Slavic vocabulary, of ancient and modern East languages, united in the genetic paradigm, which consists of etymological families with vertices *Dati, ${ }^{*}$ Bbrati, *Imati//Imbti, *Nesti.

Keywords: vocabulary of East Slavonic languages, the historical word formation, lexical nest, etymological nest, genetic paradigm, semantics. 


\title{
К ПРОБЛЕМЕ КОНТРАСТИВНОГО ОПИСАНИЯ \\ ЛЕКСИКО-СЕМАНТИЧЕСКИХ СИСТЕМ \\ ВОСТОЧНОСЛАВЯНСКИХ ЯЗЫКОВ В ДИАХРОНИЧЕСКОМ АСПЕКТЕ
}

\author{
(Резюме)
}

В статье затрагиваются вопросы диахронического описания генетически близкой лексики восточнославянских языков на основе исследования её происхождения и семантики в соответствии с актуальными проблемами исторической дериватологии, лексикологии и лексикографии славянских языков.

Ключевые слова: лексика восточнославянских языков, историческая дериватология, лексическое гнездо, этимологическое гнездо, генетическая парадигма, семантика. 